\title{
APRESENTAÇÃO DA SEÇÃO TEMÁTICA - GENÉRICOS DISCURSIVOS: ENUNCIAÇÃO, MEMÓRIA E HISTÓRIA
}

\author{
PAULA CHIARETTI ${ }^{1}$ \\ LEDA VERDIANI TFOUNI ${ }^{2}$ \\ Organizadoras
}

Programa de Pós-Graduação em Ciências da Linguagem - PPGCL

Universidade do Vale do Sapucaí - Univás

Avenida Prof. Tuany Toledo, 470 - 37550-000, Pouso Alegre-MG - Brasil

Universidade de São Paulo - USP

Rua Maria Octavia P. Villa, 71 - 14021-047 - Ribeirão Preto-SP - Brasil

chiaretti.paula@gmail.com , lvtfouni@usp.br

\begin{abstract}
Resumo. Com o objetivo de apresentar a seção temática do número 22 da revista, o texto introduz algumas articulações teóricas que buscam explicar o funcionamento dos genéricos discursivos e apresenta os artigos que foram aceitos para publicação.
\end{abstract}

Palavras-chave: Genéricos discursivos; fórmulas; língua; discurso.

\begin{abstract}
In order to present the issue 22 of this journal thematic section, the text introduces theoretical articulations that aim to understand the functioning of discursive generics and presents the articles that have been accepted for publication.
\end{abstract}

Keywords: Discursive generics; formulae; language; discourse.

Nossa tarefa, ao propor sessão temática que abordasse os genéricos discursivos, era dupla: primeiro, trazer a público a complexidade dessas formulações, mostrando sua importância central na atividade linguageira e literária de um grande número de culturas, ao mesmo tempo em que se procurava compreender o processo de produção de sentidos em jogo nessa materialidade discursiva; segundo, dar continuidade, através de um leque mais amplo, aos inúmeros trabalhos de pesquisa de iniciação científica, mestrado e doutorado $^{3}$ realizados junto ao grupo de pesquisa A AD e suas Interfaces, coordenado por Leda Verdiani Tfouni.

\footnotetext{
${ }^{1}$ Docente no Programa de Pós-Graduação em Ciências da Linguagem - PPGCL / Univás.

${ }^{2}$ Professora Titular na Faculdade de Filosofia, Ciências e Letras de Ribeirão Preto - USP. Pesquisadora $1 \mathrm{~A}$ do CNPq.

${ }^{3}$ Romero, 2017; Silva, 2015; Paulon, 2014; Santos; 2014; Bartijotto, 2014; Adorni, 2010; Santos, 2008; Chiaretti, 2008; Paula, 2008; Sarti, 2007; Mouraria, 2005; Pereira, 2005; Petean, 2004; Molena, 2003; Pantoni, 2002; Moraes, 2002; Santos, 2001; Silva, 2000; Ferrioli, 2000; Assolini, 1999; Carreira, 1997; Boni Jr., 2019; Molena, 2018; Gomes, 2016; Santos, 2015; Chiaretti, 2013; Monte-Serrat, 2013; Sarti, 2011; Pereira, 2010; Maestrelli, 2010; Laureano, 2008; Assolini, 2003; Ferriolli, 2003; Romão, 2002; Pauli, 2002;
} 
A proposta publicada trazia o seguinte objetivo: Esta seção temática se dedicará a publicar textos que busquem trabalhar em suas articulações teóricas e analíticas questões pertinentes à compreensão do funcionamento da linguagem de genéricos discursivos tais como provérbios, slogans, máximas, rezas, fórmulas adivinhatórias, ditos populares, que constituem resumos historicamente constituídos das experiências e atividades do homem sobre o (no) mundo, e codificam os valores e crenças de uma cultura, que se caracterizam por ser fórmulas que codificam o conhecimento do mundo e da experiência factual de gerações e que ficam condensadas em um único enunciado, como: "Homem não chora", "É de pequenino que se torce o pepino", ou "Jogou fora o bebê com a água da bacia" (este último é um dito popular que mostra a relação com o humor). Os genéricos derivam de uma cristalização de repetições linguageiras, de cunho deôntico (em geral, contêm um "ensinamento de ordem moral). São enunciados mínimos, de estrutura sintática simples. De modo geral, podemos afirmar que esse discurso se caracteriza por produzir um efeito de atemporalidade, apresentando-se como a-histórico, de modo a dissimular o caráter contingente da sua formulação. Passando, então, da objetividade e do efeito de eficácia que o genérico discursivo produz para a complexidade dessa formulação, tínhamos a expectativa de que os trabalhos publicados nesta seção temática se voltassem a compreender o processo de produção de sentidos em jogo nessa materialidade discursiva.

O produto dessa con(pro)vocação - apresentado neste número - traz trabalhos heterogêneos do ponto de vista teórico e metodológico, assim como dos objetos discursivos selecionados, de tal forma que o tema ganhou outras dimensões e abrangências.

Assim é que, no artigo "Pra burro só falta a pena", Claudete Guiraldello inicialmente apresenta as perspectivas da Retórica (Reboul) e da Análise de discurso de base enunciativa (Maingueneau) sobre os slogans, usando esses autores como mote para uma discussão sobre os provérbios, e toma "“...] esses estudos como ponto de partida para apresentar algumas reflexões sobre o uso de provérbios, a partir do quadro de referências teórico da $\mathrm{AD}$ e da psicanálise lacaniana". Ghiraldello apresenta aos leitores uma valiosa retrospectiva do modo como a psicanálise lacaniana enfatiza a importância de o analista privilegiar em sua escuta o uso de provérbios. Essa observação não serve só para a psicanálise de divã, acrescentamos, mas também para a prática de todo tipo que privilegie um paradigma indiciário.

Elisson Ferreira Morato inicia o artigo "Generalização discursiva e enunciação nas cantigas de congado em Minas Gerais: uma abordagem semiolinguística" focalizando os "saberes de mundo" e colocando em destaque "[...] formas de explicação através das quais os sujeitos se posicionam em sua enunciação de modo que seu discurso se assemelhe a uma voz única formada pela voz de todos: uma enunciação em uníssono. Esses discursos podem ser observados em vários grupos ou segmentos sociais, e se manifestam de maneira relevante em determinadas manifestações da cultura popular afrobrasileira, dentre as quais as cantigas do congado". Tendo como condutor teórico os conceitos de generalização discursiva, meta-enunciação e a teoria da Semiolinguística

Pacífico, 2002; Santoro, 2002; Carreira, 2000; Freire, 1990; Silveira, 2010; Ligeiro, 2010; Santos, 2009; Romero, 2009; Silva, 2009; Santos, 2007; Godoi, 2002; Pereira, 2002; Marques, 1999; Melo, 1998; Lopes, 1997; Caron, 1995; Coleta, 1995; Venturini, 1995; Mian, 1993; Silva, 1993; Carreira, 1993; Abrahão, 1992; Garcia. 1992; Ribeiro, 1992; Paiva, 1992; Alvares, 1991; Cavalcanti, 1991; Bó, 1990; Vianna, 1990. 
(Charaudeau), Morato enfatiza que a relevância desse estudo está no fato de que "[...] a generalização discursiva permite que o discurso dado pela tradição oral se sustente graças a uma, diríamos, distribuição de responsabilidades enunciativas".

No artigo de Lafity dos Santos Alves e Francisco Alves Filho, intitulado "Memória discursiva: a ressignificação dos ditados populares em letras de música brasileiras como forma de criticar os sujeitos em seus diferentes papeis sociais", os autores pretendem analisar como a memória discursiva, conforme proposta de Pêcheux, se presta a elucidar a ocorrência de ditados em letras de música. Partem do pressuposto de que o interdiscurso e a memória discursiva são elementos relevantes na/para a constituição do discurso dos ditados utilizados em letras de música, materiais de análise dessa pesquisa. Os autores analisam as letras de quatro músicas e afirmam que o uso de ditados populares se presta ao resgate de algum acontecimento histórico e servem "[...] como forma de criticar um comportamento social dos sujeitos - no exercício dos seus diferentes papeis sociais".

Filando-se à Neuroliguística, Nathália Luiz de Freitas dedica-se a identificar e caracterizar a emergência de estratégias metadiscursivas - metaformulativas, modalizadoras e metaenunciativas $(\mathrm{KOCH}, 2004)$ - na interpretação de provérbios metafóricos por afásicos no artigo "Estratégias metadiscursivas envolvidas na interpretação de provérbios metafóricos por pessoas com afasia". Através de uma pesquisa com sujeitos afásicos, a autora procura "[...] identificar e caracterizar a emergência de estratégias metadiscursivas, metaformulativas, modalizadoras e metaenunciativas $(\mathrm{KOCH}, 2004)$ - na interpretação de provérbios metafóricos por afásicos". Uma estratégia saliente detectada por Freitas anota que os sujeitos demonstram que reconhecem que têm dificuldade para acompanhar o "percurso interpretativo das expressões". Além disso, afirma a autora que "Os participantes da pesquisa expõem, descrevem ou mesmo comentam sobre os obstáculos com os quais se deparam em suas tentativas de interpretação metafórica", e conclui que "essa postura evidencia uma atitude reflexiva quanto ao que se diz ou ao que não se é capaz de dizer e com relação à própria natureza da atividade enunciativa em curso".

Situando-se em pauta feminista e de estudos de gênero, o artigo "'Mas ele nunca me bateu': efeitos de sentido em circulação no nome de uma página do Instagram", as autoras Jennifer Souza Alvares e Larissa Montagner Cervo inicialmente trazem uma lista de provérbios e ditos populares que desqualificam a mulher por ser mulher ("Lugar de mulher é na cozinha"), e assinalam que tais genéricos pertencem a uma "[...] formação discursiva machista, sobretudo aquela que diz respeito à violência de gênero que acomete, na especificidade de nosso trabalho, as mulheres brasileiras". Passam a colocar que seu objeto de análise é a nomeação de um perfil nas redes sociais - @maselenuncamebateu com a finalidade de analisar o "[...] modo como pelo deslocamento dos sentidos produzidos por esse genérico discursivo circulante, ainda, no Brasil, as colaboradoras que administram os conteúdos publicados contribuem para a quebra do significante de tal dito e remetem às violências outras que não apenas a física como forma de romper a integridade da mulher, focando no âmbito doméstico". O objetivo do artigo é desnaturalizar o sentido dominante segundo o qual a violência é evidenciada pelas marcas no corpo. 
Todos os artigos submetidos para essa seção temática foram avaliados por parecerista ad hoc da revista Entremeios, tendo seguido o processo editorial que a publicação exige.

Nossa expectativa é que esta publicação dê início a uma série de pesquisas e trabalhos sobre os genéricos discursivos, não apenas por seu valor enquanto tesouro cultural, como também por ser um terreno fértil para que analistas dos estudos da linguagem e da psicanálise investiguem facetas ainda obscuras das relações entre sujeito, ideologia e produção de sentido.

Ribeirão Preto, 16 de dezembro de 2020.

Leda Verdiani Tfouni e Paula Chiaretti

Artigo recebido em: dez. de 2020.

Aprovado e revisado em: dez. de 2020.

Publicado em: dez. de 2020.

Para citar este texto:

CHIARETTI, Paula; TFOUNI, Leda Verdiani. Apresentação da Seção Temática - Genéricos Discursivos: enunciação, memória e história. Entremeios [Revista de Estudos do Discurso, ISSN 2179-3514, on-line, www.entremeios.inf.br], Seção Estudos, Programa de Pós-Graduação em Ciências da Linguagem (PPGCL), Universidade do Vale do Sapucaí (UNIVÁS), Pouso Alegre (MG), vol. 22, p. 218-221, jul. - dez. 2020.

DOI: http://dx.doi.org/10.20337/ISSN2179-3514revistaENTREMEIOSvol22pagina218a221 